\title{
Efficacy of Computed Tomography-assisted Limited Decompression in the Surgical Management of Thoracolumbar Fractures With Neurological Deficit
}

\section{Landa Shi}

Zhengzhou University First Affiliated Hospital

\section{Dean Chou}

University of California San Francisco

\section{Yuqiang Wang}

Zhengzhou University First Affiliated Hospital

\section{Mirwais Alizada}

Zhengzhou University First Affiliated Hospital

Yilin Liu (D liuyilin202013@163.com )

Zhengzhou University First Affiliated Hospital

Research article

Keywords: CT-assisted, Thoracolumbar Fractures, Precision Medicine, ERAS, limited decompression

Posted Date: February 3rd, 2021

DOl: https://doi.org/10.21203/rs.3.rs-157719/v1

License: (c) (i) This work is licensed under a Creative Commons Attribution 4.0 International License. Read Full License

Version of Record: A version of this preprint was published at Journal of Orthopaedic Surgery and Research on April 14th, 2021. See the published version at https://doi.org/10.1186/s13018-021-02388-4. 


\section{Abstract}

Objective: to investigate the effect of CT-assisted limited decompression in the management of single segment A3 lumbar burst fracture.

Method: A retrospective study of 106 cases with a single-level Magerl type A3 lumbar burst fractures treated with short-segment posterior internal fixation and limited decompression from January 2015 to June 2019 was performed. Patients were divided into two groups: CT-assisted and non-CT-assisted. Perioperative factors, clinical outcomes, postoperative complications, imaging parameters and healthrelated quality of life (HRQoL) were evaluated.

Results: There was no significant difference between the two groups in the kyphosis, anterior vertebral body height loss, posterior vertebral body height loss, operative time, and postoperative complications. The visual analogue score (VAS) and spinal canal encroachment in the CT-assisted group were lower than those in the non-CT-assisted group $(P<0.05)$. The Japanese Orthopaedic Association score $(J O A)$, the simplified HRQoL scale and American Spinal Injury Association (ASIA) Spinal Cord Injury Grade in the CT-assisted group were higher than those in the non-CT-assisted group $(P<0.05)$.

Conclusion: CT-assisted limited decompression in the treatment of single-segment A3 lumbar burst fracture can achieve better fracture reduction and surgical results, and improve the long-term recovery of neurological function and quality of life of the patients.

\section{Full Text}

This preprint is available for download as a PDF.

\section{Tables}

Due to technical limitations, tables PDF is only available as a download in the Supplemental Files section.

\section{Figures}




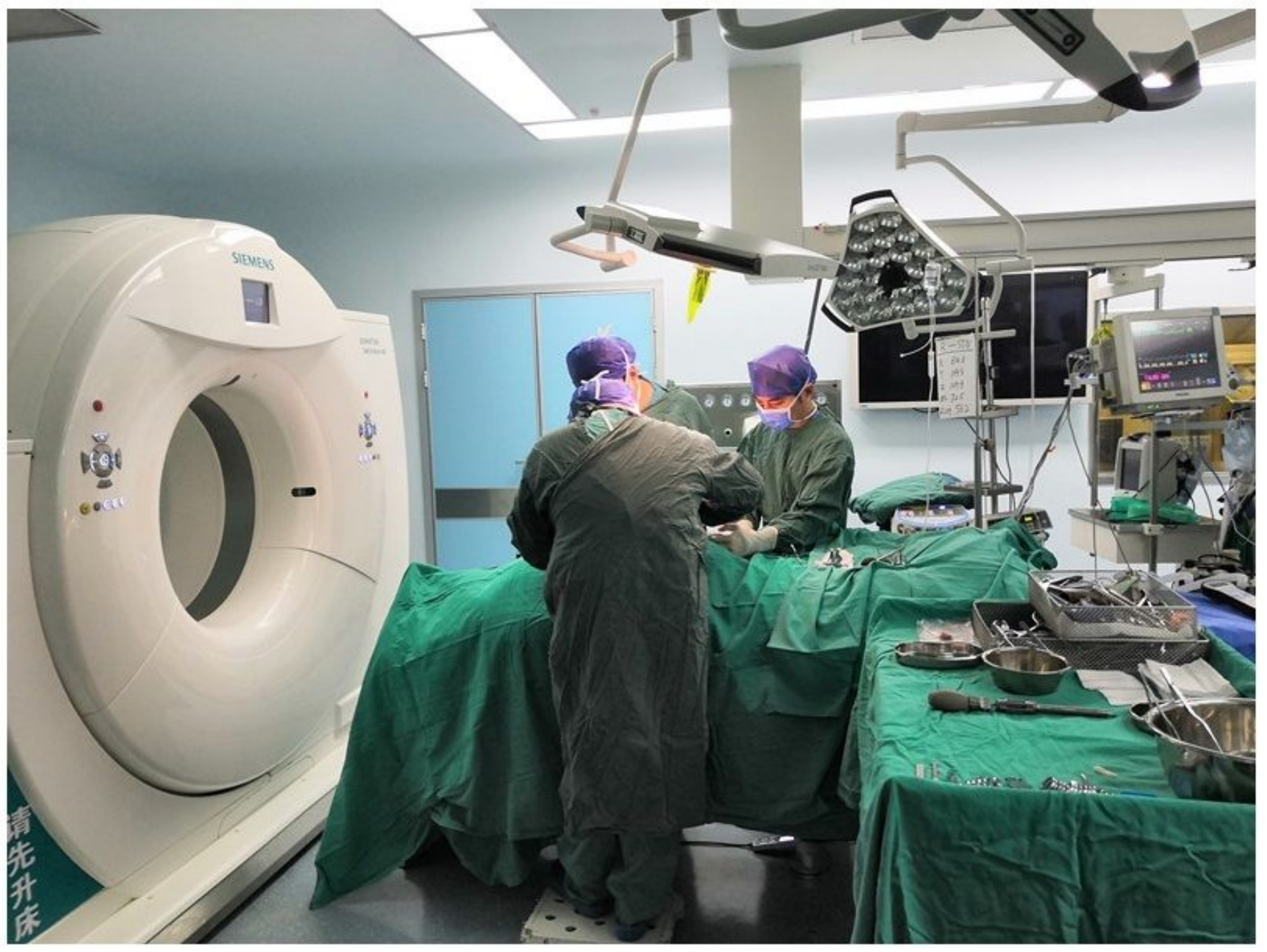

Figure 1

Photos of surgical procedures 


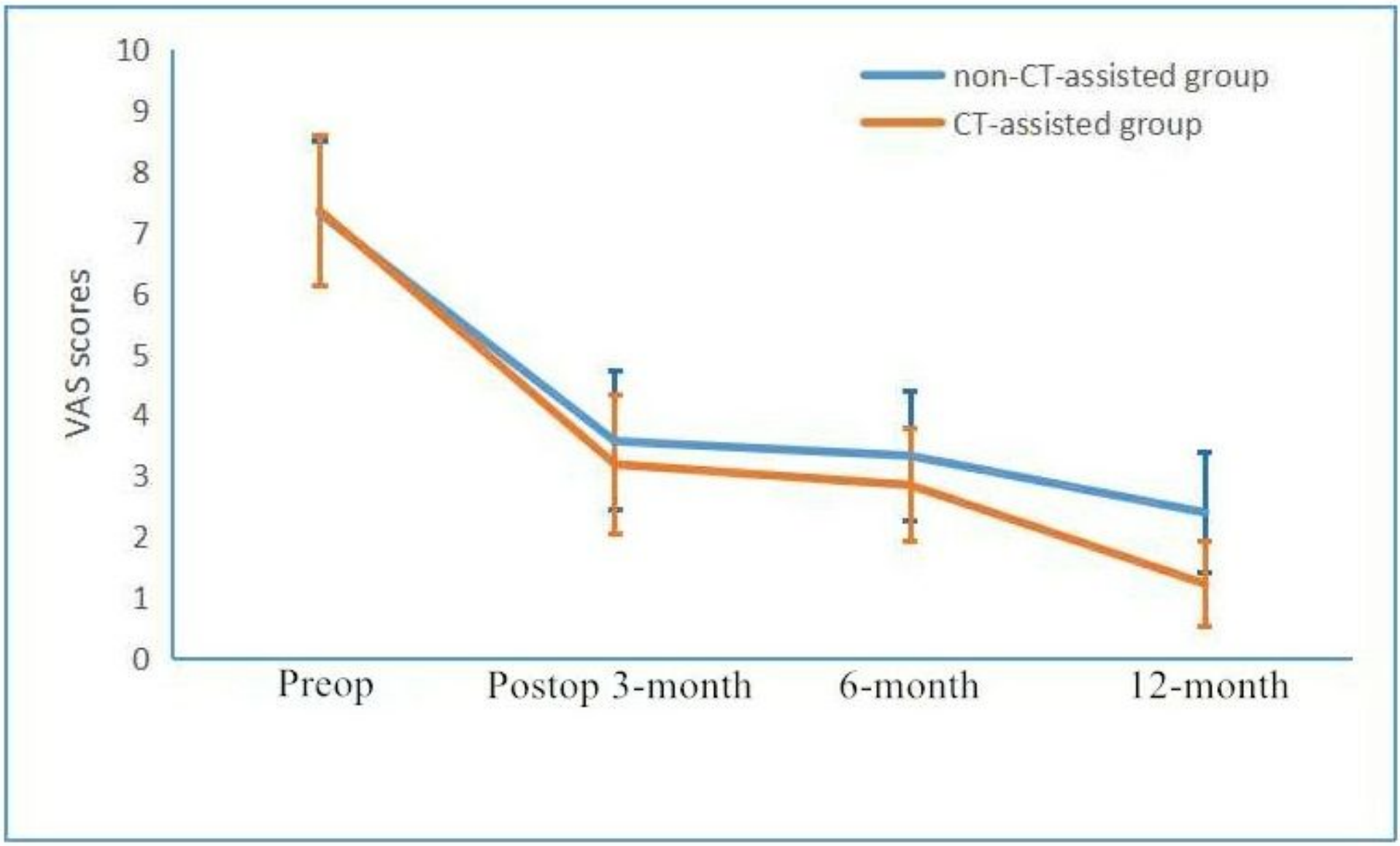

Figure 2

The VAS score of the CT-assisted Group at 12 months was significantly lower than that of the non-CTassisted Group. 


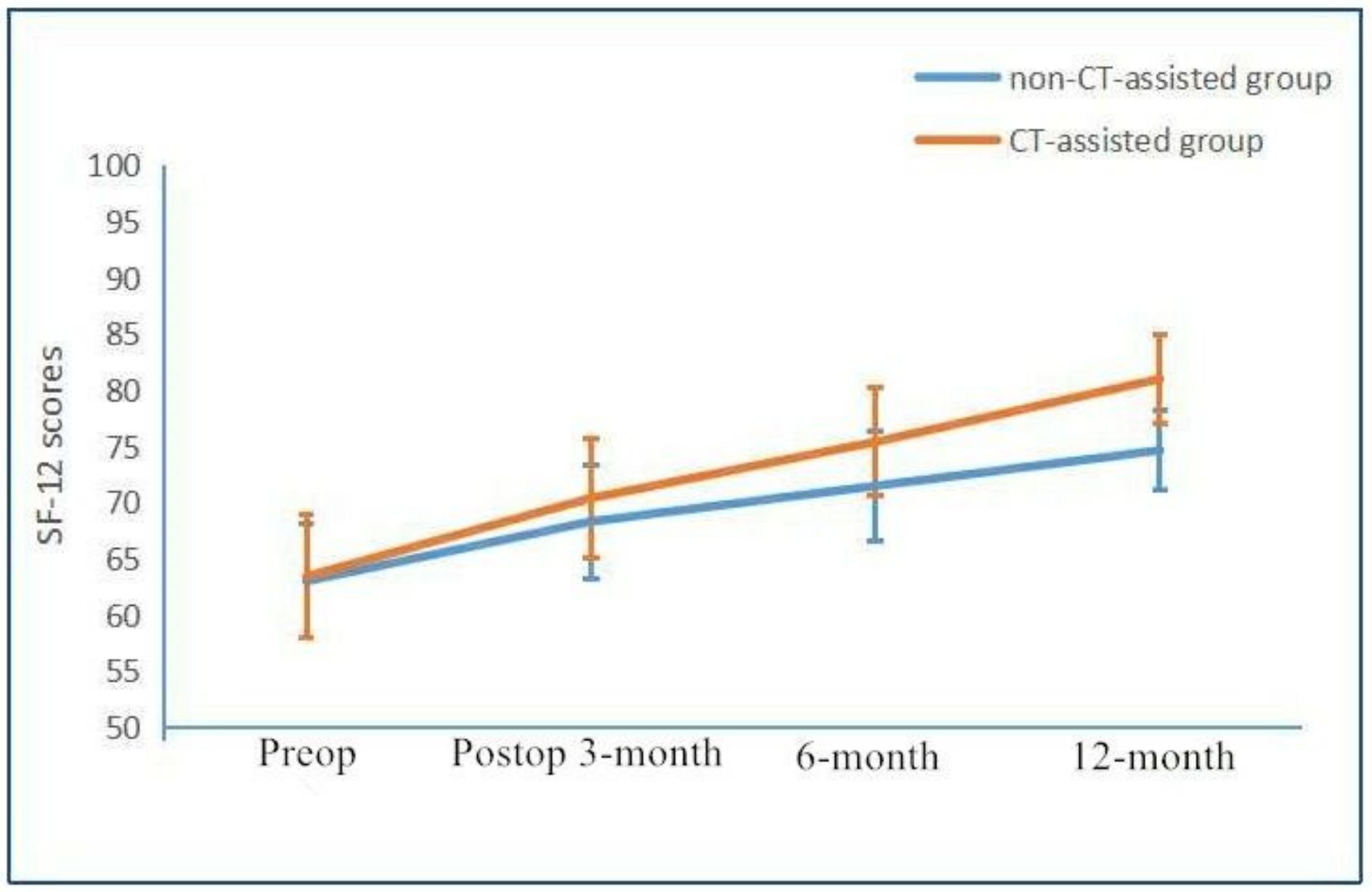

\section{Figure 3}

The SF-12 score of the CT-assisted Group at 12 months follow up was significantly higher than that of the non-CT-assisted Group. 

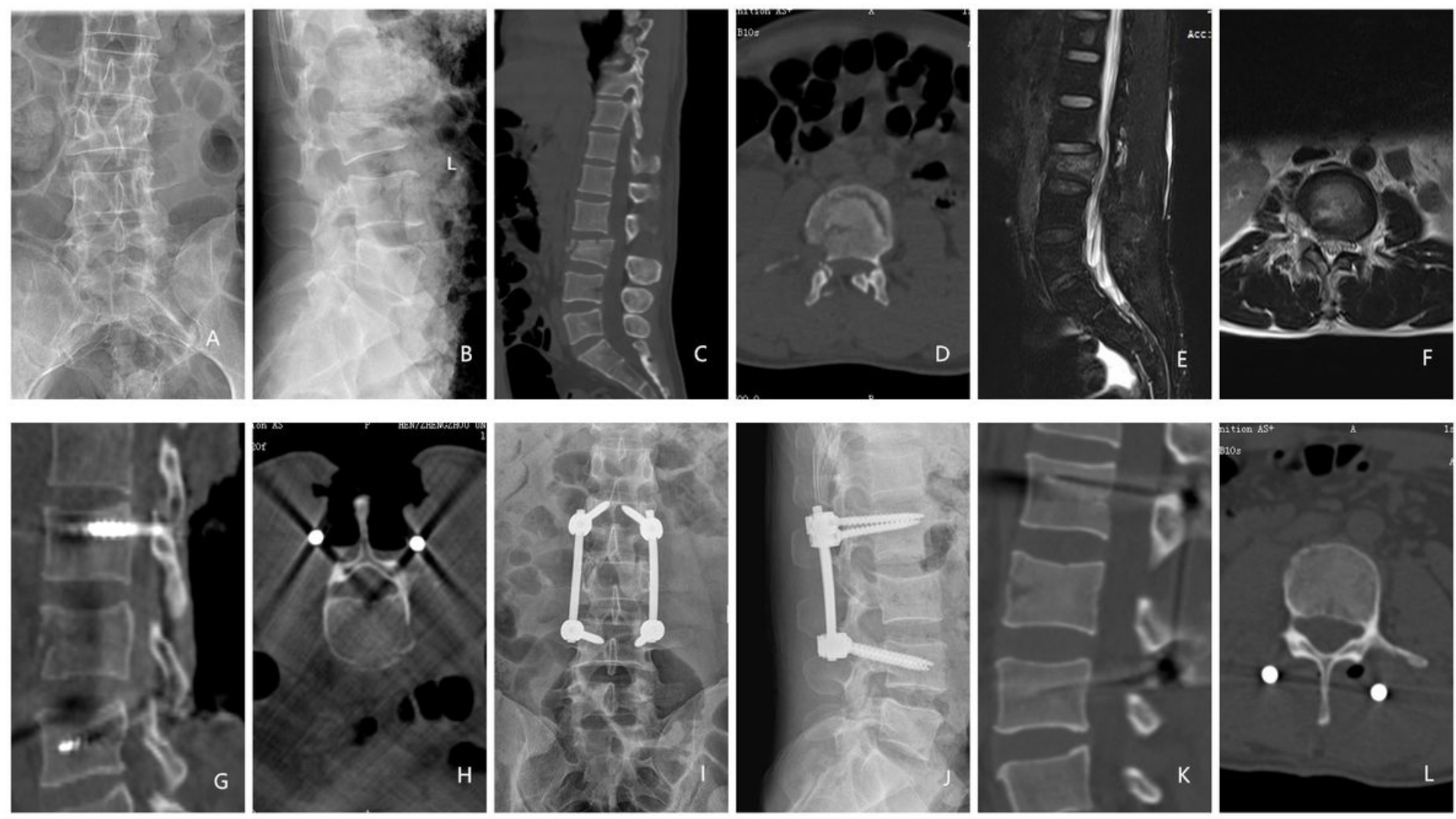

\section{Figure 4}

A 23-year-old male presented with a burst fracture of the $L 3$ vertebral body. Severe back pain with limited mobility and left lower limb muscle strength grade-II. A-F are the preoperative imaging data, $\mathrm{G}$ and $\mathrm{H}$ are the intraoperative CT scanning data, and $\mathrm{I}-\mathrm{L}$ are the 12-month postoperative imaging data. Preoperative CT scan showed the fracture fragment burst into the spinal canal (C, D), MRI showed the dural sac was compressed $(E, F)$, the diameter of spinal canal returned to normal, the pressure of dural sac disappeared $(G, H)$, the result was satisfactory $(I-L) 12$ months after the operation, and the muscle strength of left lower limb was grade $\mathrm{V}$. 

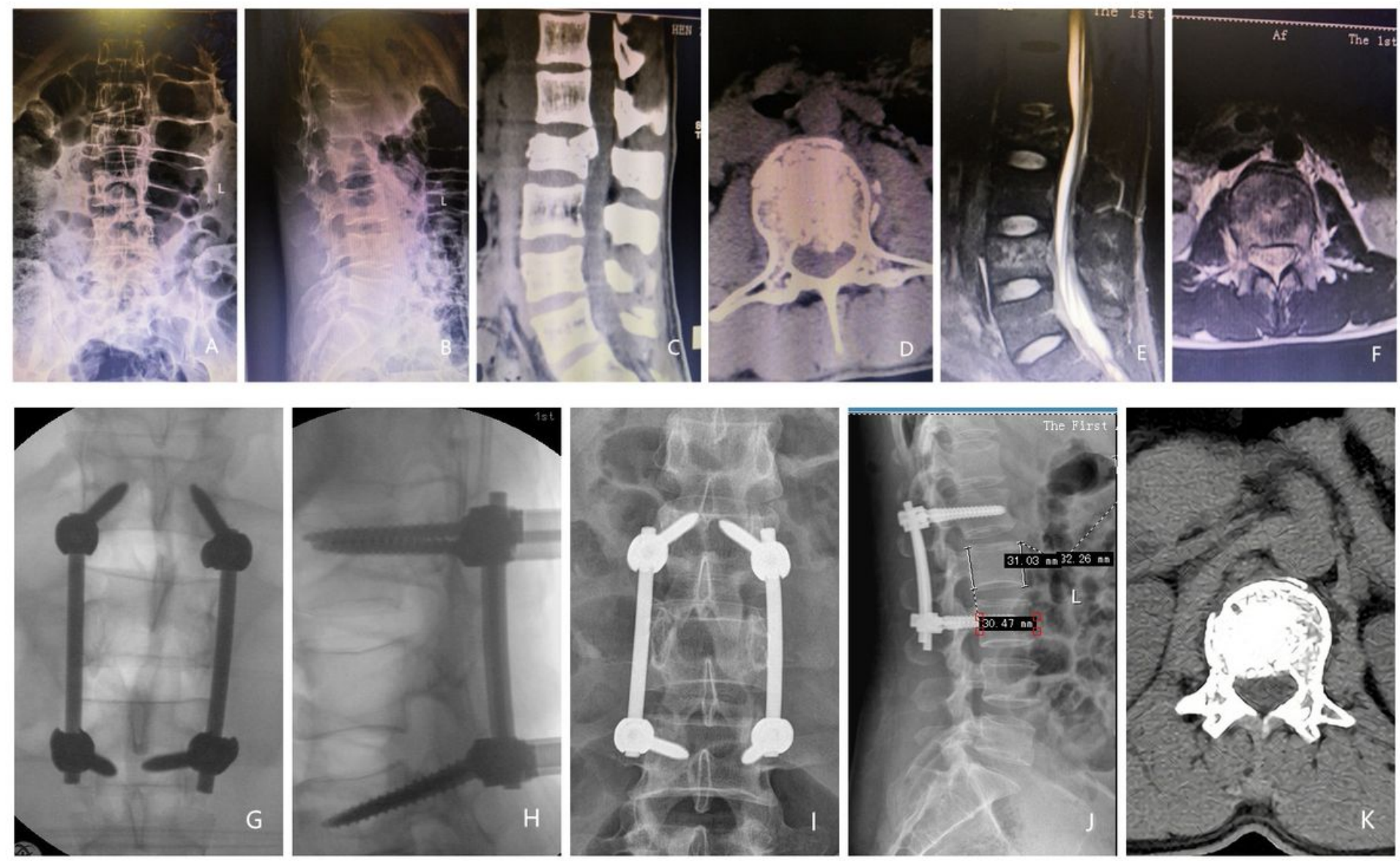

\section{Figure 5}

A 42-year-old male presented with a burst fracture of the L2 vertebra. Low back pain from a high fall and limitation of movement of both lower limbs. A-F are the preoperative images. G-H are C-arm fluoroscopy after bilateral limited decompression. I-K are the postoperative imaging data at a 12-month follow-up visit. Preoperative imaging data show the fractures compressed the dural sac (C, D, E, F), and bilateral limited decompression was performed after multiaxial pedicle screw fixation. At the 12-month postoperative visit, the fracture healing is satisfactory $(\mathrm{I}-\mathrm{K})$, and the muscle strength of both lower limbs was grade $\mathrm{V}$.

\section{Supplementary Files}

This is a list of supplementary files associated with this preprint. Click to download.

- Table.pdf

- renamed8e28e.xls 